\title{
Thermal radiation as a learned orientation cue in leaf-cutting ants (Atta vollenweideri)
}

\author{
C.J. Kleineidam ${ }^{\mathrm{a}, *}$, M. Ruchty ${ }^{\mathrm{a}}$, Z.A. Casero-Montes ${ }^{\mathrm{b}}$, F. Roces ${ }^{\mathrm{a}}$ \\ ${ }^{a}$ Department of Behavioral Physiology and Sociobiology, University of Würzburg, Biozentrum, Am Hubland, 97074 Würzburg, Germany \\ ${ }^{\mathrm{b}}$ Department of Physiology, Universidad Pablo de Olavide, Anatomy and Cellular Biology, Carretera de Utrera Km. 1, 41013 Sevilla, Spain
}

\begin{abstract}
We explored the ability of leaf-cutting ants (Atta vollenweideri) to learn the location of a food reward by using thermal information as an orientation cue. During training of single workers, the conditioned stimulus was a distant thermal source placed frontally, $15 \mathrm{~mm}$ away from a platform having a leaf fragment as reward. After training, single workers were confronted with the choice between two sides, one being coupled, in a pseudo-randomized design, with a thermal stimulus heated $5^{\circ} \mathrm{C}$ above environmental temperature. After 10 learning trials, workers significantly chose the side with the thermal stimulus. This showed that workers can use thermal information for spatial orientation in the context of foraging, which may help them to locate, for instance, highly attractive sun-exposed leaves. Thermal radiation alone as orientation cue was sufficient to allow learning, since preclusion of thermal convection during training and test did not impair workers' response. Shielding of both thorax and gaster from the thermal source did not weaken learning, suggesting the sole participation of head and antennae in temperature reception. A thermal stimulus heated $1{ }^{\circ} \mathrm{C}$ above environmental temperature could not be used as a learned orientation cue, even when foragers were allowed to directly contact the thermal source.
\end{abstract}

Keywords: Orientation; IR-radiation; Insects; Hymenoptera; Learning

\section{Introduction}

Environmental temperature plays a decisive role in the metabolism and energy balance of ant societies, since ants are essentially ectothermic (Heinrich, 1993). Temperature primarily affects both worker activity by inhibiting or reducing foraging, as well as the speed of brood development, parameters that directly determine the growth rate of a colony (Porter, 1988; Porter and Tschinkel, 1993). Excessive temperatures negatively affect colony growth by reducing brood survival and worker longevity (Calabi and Porter, 1989; Roces and Núñez, 1989). Since temperature can have a massive effect on ant colony fitness, behavioral adaptations to cope with seasonal variations in environmental temperature, as well as with the naturally

\footnotetext{
*Corresponding author. Tel.: + 499318884312 ; fax: + 499318884309

E-mail address: kleineidam@biozentrum.uni-wuerzburg.de (C.J. Kleineidam).
}

occurring daily temperature fluctuations, are expected to occur (Roces, 1995; Roces and Núñez, 1996; Steiner, 1929).

Long-term thermal regulatory responses of ants have been described at the individual and colony level. They involve, for instance, the selection of a suitable place to locate the nest by founding queens (Brian, 1952), and the construction of nest mounds that to some extent compensate the natural fluctuations of climatic parameters (Frouz, 1996; Kleineidam et al., 2001; Scherba, 1962). Short-term responses for temperature control in ants involve, for instance, behavioral tracking of preferred temperatures inside the nest, and transporting the brood to the selected values (Brian, 1973; Roces and Núñez, 1989).

Leaf-cutting ants of the genus Atta construct the largest ant nests, which house up to 5 million individuals and may contain up to 7000 underground chambers, mainly for fungus cultivation on collected leaf material (Autuori, 1941; Moreira et al., 2004a,b). The fungus gardens represent the sole food source for the developing larvae, and they have strict demands of high humidity and 
temperatures between 25 and $30^{\circ} \mathrm{C}$ for proper growth (Powell and Stradling, 1986; Quinlan and Cherrett, 1978). As a consequence, workers are expected to maximize the growth of their symbiotic fungus not only by selecting suitable vegetable substrate, but also by an active manipulation of climatic conditions and proper location for fungus cultivation inside the nest. For instance, workers of a laboratory colony of Atta sexdens rubropilosa were observed to relocate the fungus garden along a humidity gradient, choosing the environment with the highest humidity (Roces and Kleineidam, 2000). Regarding temperature control, workers of the leaf-cutting ant Acromyrmex heyeri relocate the fungus and select temperatures that closely match the thermal range in which maximal growth of the symbiotic fungus occurs (Bollazzi and Roces, 2002).

A prerequisite for the control of nest climate, and ultimately colony growth, is the ability of workers to precisely sense the relevant nest climate parameters, such as humidity, carbon dioxide and temperature. Leaf-cutting ant workers have been shown to be equipped with thermoand $\mathrm{CO}_{2}$-sensitive antennal sensilla (Kleineidam et al., 2000; Kleineidam and Tautz, 1996). The responses to $\mathrm{CO}_{2}$ concentrations were shown to be relevant in the context of nest ventilation (Kleineidam et al., 2001; Kleineidam and Roces, 2000).

Relocation of brood and fungus as a thermoregulatory response in leaf-cutting ants (Bollazzi and Roces, 2002) implies the use of temperature as an orientation cue. Temperature information may also serve outside the nest as an additional orientation cue, together with chemical, visual, gravitational and magnetic information (Vilela et al., 1987), when foraging workers explore the area around their nest. And it may also help foraging workers, upon arrival at a food plant, to find leaves warmed by the sun, which have been shown to be highly palatable (Folgarait et al., 1996; Nichols-Orians, 1991).

In the present study, we explored the ability of workers of the leaf-cutting ant Atta vollenweideri, in a foraging context, to learn the location of food by using thermal information for orientation. Further, we investigated whether the temperature response of the ants is based on the reception of convective heat or thermal radiation. In addition, we assessed the temperature difference necessary to allow learning of a heat source, both, in far range (by reception of thermal radiation or convective heat) and in contact range (by reception of conductive heat).

\section{Materials and methods}

\subsection{Animals}

The colony of $A$. vollenweideri (Forel) used in the experiments was collected in 2002 at the Reserva Ecológica El Bagual, Formosa, Argentina (Bollazzi M. and Geissler O.). It was reared at the Biozentrum, University of Würzburg, in an environmental chamber at $26^{\circ} \mathrm{C}$ and $50 \%$ relative humidity in a $12 \mathrm{~h} / 12 \mathrm{~h}$ photoperiod, and fed mainly with privet leaves (Ligustrum vulgaris) and dog rose (Rosa canina). At time of the experiments, the fungus garden occupied a volume of about 121 in nine plastic boxes $(19 \mathrm{~cm} \times 19 \mathrm{~cm} \times 9 \mathrm{~cm}$ each $)$, interconnected with plastic tubes. One of the plastic boxes was used as central feeding box ( $\mathrm{CF}$ box) at times when no experiments were done. During the experiments, the $\mathrm{CF}$ box was connected via a wooden bridge of $1 \mathrm{~m}$ with a perpendicular bifurcation $(0.45 \mathrm{~m}$ each) to two additional feeding boxes. The colony had free access to the two feeding boxes. Foragers were allowed to carry leaf fragments from the feeding boxes and to develop two foraging columns (established trails) merging at the bifurcation (Fig. 1A).

\subsection{Training procedure}

For the experiments, single outgoing foragers were gently branched off from the wooden bridge, onto a wooden toothpick. While on the toothpick for the first time, the foragers were marked on one leg or thorax with a small dot of water-soluble white out fluid (Tipp-Ex, Clichy Cedex, France) for individual identification during training and test. The toothpick was then briefly connected for transfer of the forager to a wooden training stick (TS) on which training took place (see Fig. 1B, left). Once on TS, the forager encountered a leaf fragment, picked it up in most cases, and turned back to return to the nest. The toothpick was used again for transfer, to allow the marked forager to return to the bridge and to enter the foraging column. Typically, a successful forager dropped the carried fragment on the trail after having walked 10 or $20 \mathrm{~cm}$, turned back and tried to return to the discovered "foraging site" within a few minutes. Under natural conditions, this is a common behavior that allows the rapid branching and establishment of a secondary trail when an alternative food source is discovered (Hubbell et al., 1980; Röschard and Roces, 2003a,b). It is therefore possible to maintain an experienced worker foraging solitarily along such a sidetrail, repeating this cycle of picking a fragment, dropping it upon arrival at the foraging column, and returning to the side-trail. Occasionally, some foragers were observed to return to the foraging column without collecting the leaf fragment they encountered on the platform. After a brief interaction with nestmates on the bridge, they returned to the spot from where they were transferred to the TS, and looked for the TS to reach again the platform with the leaf fragment. Such foragers, although unloaded, typically enforce recruitment of nestmates by laying pheromone trails (Jaffe and Howse, 1979; Geissler O., pers. comm.), so that such foraging cycles were also considered successful training trials. Because of the training of freely foraging workers in an appetitive context, the intervals between successive training trials varied between 1 and about $10 \mathrm{~min}$. Nevertheless, this procedure was preferred, instead of forcing workers to make decisions at regular time intervals. 

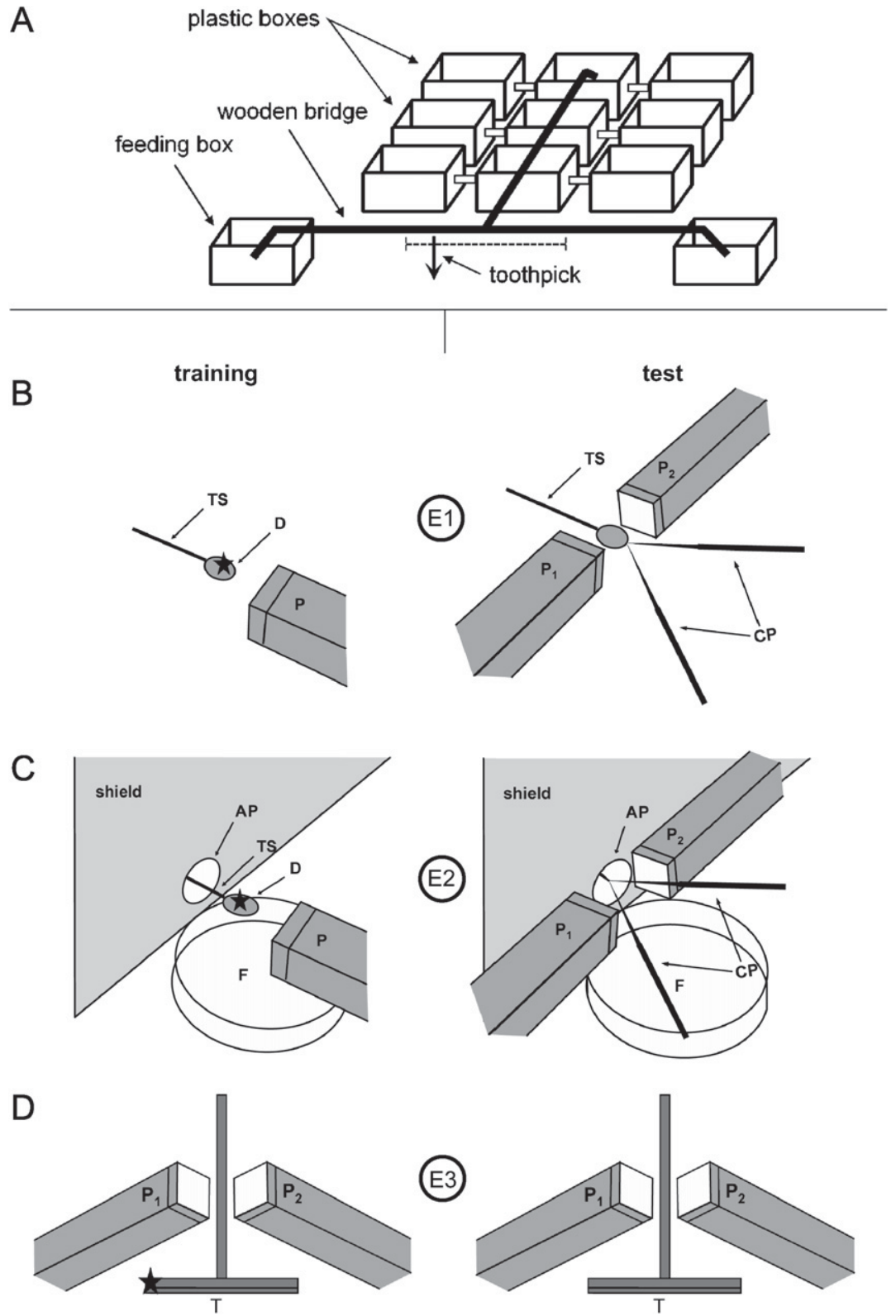

Fig. 1. Foraging-, training- and test-setups for the experiments E1, E2 and E3. (A) Arrangement of nest boxes and foraging setup with wooden bridge, bifurcation and two feeding boxes. The colony established foraging columns along the wooden bridge to the two feeding boxes. Single foragers were then branched off with a toothpick in an area indicated by the dashed line, and gently transferred to one of the experimental setups shown below. (B) Training(left) and test-setup (right) for the learning experiment (E1). During training (on the left), single foragers approached the reward (leaf fragment, indicated by a star) on the platform (D) via the training stick (TS), and experienced the thermal stimulus (P: Peltier plate) ahead. In the test situation (on the right), two Peltier plates $\left(\mathrm{P}_{1}\right.$ and $\left.\mathrm{P}_{2}\right)$ were mounted on both sides of the platform and two choice sticks $(\mathrm{CP})$ were offered at the distal end of the platform. $(\mathrm{C})$ Training- (left) and test-setup (right) for the radiation-convection experiment (E2). During training (on the left), the approaching foragers had to pass an aperture (AP) in a shield before reaching the platform (D) with the reward (star). A constant and laminar airflow from a tube (F) was used to remove thermal convection from the platform and the forager. In the test situation (on the right), two Peltier plates $\left(\mathrm{P}_{1}\right.$ and $\left.\mathrm{P}_{2}\right)$ were mounted on both sides of the shield and two choice sticks (CP) were offered at the distal end of the training stick (TS). (D) Training- (left) and test-setup (right) for the radiationconduction experiment (E3). During training (on the left), the approaching foragers passed two Peltier plates $\left(\mathrm{P}_{1}\right.$ and $\left.\mathrm{P}_{2}\right)$, both of which could be touched with the antennae. One of the plates was heated. The reward (star) was offered at the same side as the heated Peltier plate on one end of the bifurcation (T). In the test situation (on the right), the arrangement was similar but no reward was offered.

\subsection{Testing procedure}

Single foragers were challenged to learn the location of a leaf fragment as reward by using a heated object as orientation stimulus. Foragers of the control groups did not experience a heated object during training, and experienced the same conditions in the non-rewarded test situation as the experimental groups. In the test situation, the majority of foragers decided quickly for one of both sides $(<5 \mathrm{~s})$. Only a few turned back and left the decision point, which lead to the removal of these foragers from the analysis. The foragers' learning abilities were tested in a 
non-rewarded choice situation by comparing the behavior of foragers of the experimental groups vs. the control groups, so as to expose any learned thermal preference. Tested foragers and those that did not complete training were removed from the colony to avoid repeated measurements.

\subsection{Stimulus device}

Peltier plates of $15 \mathrm{~mm} \times 15 \mathrm{~mm}$ were used as warm and cold objects. The temperature of the Peltier plates was adjusted manually with a power supply and the surface temperature was measured with a contact-free thermometer (Quicktemp 850-T1, Testo, Germany). Adjusted temperatures were either $5^{\circ} \mathrm{C}$ above, $5^{\circ} \mathrm{C}$ below or $1^{\circ} \mathrm{C}$ above ambient temperature, that is 31,21 or $27^{\circ} \mathrm{C}$, respectively. One surface (front face) of the Peltier plates was covered by a foil with an emissivity of 0.93 ; the other surface was mounted on a rod for heat conduction. Changes of temperature after switching the heat/cool current were fast and almost complete after $1 \mathrm{~min}$ (Fig. 2). In steady-state use, the front face temperature was stable over a measured period of $30 \mathrm{~min}$ (data not shown).

\subsection{E1: learning experiment}

In the first experiment, we asked whether foragers are able to learn the location of a leaf fragment by using a heated object as a remote orientation stimulus, without the need of touching it with the antennae. We employed a paradigm of absolute conditioning. During training,

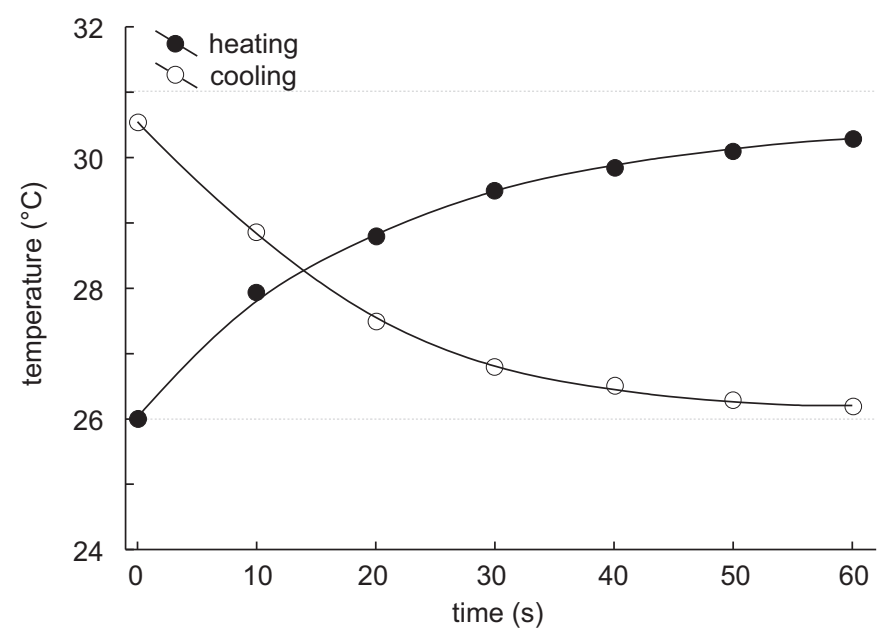

Fig. 2. Temperature change at the surface (front face) of the Peltier plate after switching on (heating; closed circles) or switching off (passive cooling; open circles) the power source. After switch-on, the temperature at the Peltier plate surface rises quickly up to the maximum of $5^{\circ} \mathrm{C}$ above ambient temperature after $60 \mathrm{~s}$. After switch-off, the temperature at the Peltier plate surface drops rapidly to almost ambient temperature of $26^{\circ} \mathrm{C}$ after $60 \mathrm{~s}$. A similar dynamic of temperature change was measured by cooling the Peltier plate to $5{ }^{\circ} \mathrm{C}$ below ambient temperature and passive warm up (data not shown). foragers on TS encountered a leaf fragment (reward) placed at the center of the platform $(\varnothing 20 \mathrm{~mm})$ at the end of TS (Fig. 1B, left). The Peltier plate was mounted in front of the approaching forager at a distance of $15 \mathrm{~mm}$ from the platform offering the reward. Thus, single foragers were about $25 \mathrm{~mm}$ away from the Peltier plate when collecting the leaf fragment. The front face of the Peltier plate was heated to $5^{\circ} \mathrm{C}$ above ambient temperature for two groups of foragers; for the control group the Peltier plate had ambient temperature. After either 5 or 10 training trials (group: 5 trials and group: 10 trials, respectively), individual foragers were tested once at a modified setting. Two Peltier plates were mounted on both sides of the platform at an equidistance of $15 \mathrm{~mm}$ (Fig. 1B, right). One was heated $5^{\circ} \mathrm{C}$ above and the other cooled $5^{\circ} \mathrm{C}$ below ambient temperature. The forager to be tested entered the platform without reward, and normally continued walking onto one of the two choice sticks (CPs) offered at the distal end of the platform. Only foragers that continued walking on one $\mathrm{CP}$ were included into the data analysis. After that, the forager was removed and its choice recorded. Sides were changed pseudo-randomly in the subsequent tests with other foragers.

\subsection{E2: radiation vs. convection}

In the previous experiment (E1), learning may be based on the perception of thermal radiation, convective heat, or both. In this experiment (E2), we asked whether convective heat or thermal radiation is the relevant stimulus that allows learning. Due to the close proximity of the Peltier plate to the forager's head, convective heat might be perceived by the forager. If convective heat acts as a relevant stimulus, removal of thermal convection should impair learning of the heated object as an orientation cue. In order to reduce the possible influence of thermal convection on temperature reception, air was blown across the platform, the forager and the Peltier plate via an air tube (diameter of $50 \mathrm{~mm}$ ) mounted below the platform (Fig. 1C). A continuous flow of air at a velocity of about $13 \mathrm{~mm} \mathrm{~s}^{-1}$ was used to drag warm air from the front face of the Peltier plates and from the platform. Inside the air tube, four layers of copper mesh were mounted to induce a laminar airflow directed upwards.

Besides reaching the antennae, thermal radiation may in addition warm the substrate the forager stands on (TS) while experiencing the thermal stimulus. Thus, temperature differences across the substrate might influence workers' response. In order to test whether the known temperaturesensitive sensilla on the antenna (Kleineidam and Tautz, 1996; Lacher, 1964) are sufficient for reception of the thermal stimulus in the learning paradigm, the radiation of the heated Peltier plate was restricted to the forager's head by a shield during testing. During training, single foragers had to pass an aperture in the shield to reach the platform with the reward (Fig. 1C, left). The front face of the Peltier plate, positioned ahead of the forager as in E1, was heated 
to $5{ }^{\circ} \mathrm{C}$ above ambient temperature (group: $5^{\circ} \mathrm{C}$ shield); for the control group the Peltier plate had ambient temperature. After 10 training trials, foragers were tested at a modified setting. The platform was removed and single foragers were not allowed to pass the aperture. Instead, the end of TS was positioned in the center of the aperture and two further sticks (CPs) were arranged as a Y-maze, as in E1 (placed horizontally and $90^{\circ}$ to each other; Fig. 1C, right). Two Peltier plates were mounted horizontally along the shield on both sides of the aperture, and at an equidistance of $15 \mathrm{~mm}$ from the center of the aperture. One was heated to $5^{\circ} \mathrm{C}$ above ambient temperature; the other was at ambient temperature. Sides were switched pseudo-randomly between successive tests. Due to the shield, solely the head of the foragers was exposed to thermal radiation during test, but not the legs or thorax. Only foragers entering one of the two CPs were included into data analysis.

\subsection{E3: radiation vs. conduction experiment}

The sensitivity of foragers to thermal radiation might be low compared to direct assessment of surface temperature by making contact with the object. In this experiment (E3), foragers were trained to learn the location of a leaf fragment by using a heated object as orientation stimulus, as previously described, and then tested whether they are also able to orient when the same object was heated to a temperature lower than that experienced during training (training at $5{ }^{\circ} \mathrm{C}$ and nonrewarded tests at either 5 or $1{ }^{\circ} \mathrm{C}$ above ambient temperature). In contrast to E1 and E2, foragers were able to touch two Peltier plates on their way to the reward (Fig. 1D, left). During training, the foragers encountered a T-maze and entered the $\mathrm{T}$ at the base. Before reaching the T-bifurcation, the single foragers passed the two Peltier plates. One of them was heated above ambient temperature, with the side chosen pseudo-randomly during training trials, while the other plate remained at ambient temperature. The reward was offered on the same side of the approaching forager as the thermal stimulus, and the worker's decision at the bifurcation was used as measure for thermal preference. Workers were tested after 10 learning trials. During testing, i.e., during the 11th visit, single workers were confronted with the same spatial arrangement, and their choice for one of the sides (both unrewarded) was recorded (Fig. 1D, right). Thus, in experiment E3, a differential conditioning paradigm rather than an absolute conditioning paradigm, as in E1 and E2 was used. Two experimental series were performed using the same training schedule, but differing in the test situation. Foragers were tested either with one Peltier plate heated $5^{\circ} \mathrm{C}$ above ambient temperature (group: $5^{\circ} \mathrm{C} @$ test), or with one Peltier plate heated $1{ }^{\circ} \mathrm{C}$ above ambient temperature (group: $1{ }^{\circ} \mathrm{C}$ (a)test). Foragers that were trained and tested once with one Peltier plate heated $5^{\circ} \mathrm{C}$ above ambient temperature (group $5{ }^{\circ} \mathrm{C} @$ test) were tested again in second test trial. In this case, the first test trial possibly acted as an extinction trial, since no reward was offered.
For the control group, the Peltier plates were at ambient temperature during the first 10 trials, and in the 11 th trial, one was heated to $5^{\circ} \mathrm{C}$ above ambient temperature (as in group $5{ }^{\circ} \mathrm{C} @$ test), allowing to control for possible spontaneous preference for thermal stimuli. Only foragers completing the 10 training trials and the test trial were included into data analysis.

\subsection{Statistical analysis}

All statistical analyses were performed using the statistic software STATISTICA 7.1 (StatSoft, Oklahoma). Differences between groups were evaluated with the $\chi^{2}$-test and Fishers exact $p$ one-tailed at a significance level of 0.05 .

\section{Results}

\subsection{Side preference}

In all experiments, the side where the thermal stimulus (heated Peltier plate) was positioned in the test situation was alternated pseudo-randomly. This was done in order to equalize a possible bias as a result of a stimulusindependent side preference. The experimental arrangement of the colony with the T-shaped wooden bridge and two feeding boxes was used to branch off foragers inline of their foraging column (Fig. 1A). Foragers showed a slight preference for one side. Pooling the worker responses $(n=190)$ recorded across all experiments revealed a side preference of $60 \%$ of foragers to the right side in the test situation $\left(\chi^{2}=3.85, \mathrm{df}=1, p<0.05\right)$. However, in none of the single experiments was the stimulus-independent side preference statistically significant.

\subsection{E1: learning experiment}

In experiment $\mathrm{E} 1$, foragers experienced the heated object during approach and collection of the reward. In the test situation, one Peltier plate was heated and the other cooled (Fig. 1B). After 10 training trials (group 10 trials, $n=20$ ), foragers showed a marked preference for the side with the heated object (learned warm preference) (Fig. 3A; $\chi^{2}=8.64, \mathrm{df}=1, p<0.01$ ). Five training trials (group 5 trials, $n=20$ ) failed to cause any thermal preference compared to the control group $(n=20)$ (Fig. 3A; $\left.\chi^{2}=0.10, \mathrm{df}=1, p=0.50\right)$. In the control experiment, foragers that experienced a heated Peltier plate only during the test showed a slight tendency, although not statistically significant, to avoid the side with the thermal stimulus, when compared with an expected 1:1 distribution of responses $\left(\chi^{2}=0.40, \mathrm{df}=1, p=0.38\right)$.

\subsection{E2: radiation vs. convection}

As in E1, foragers experienced the heated object during approach and collection of the reward. In the test situation, only one Peltier plate was heated and the other remained at 
room temperature. The experimental arrangement excluded the influence of thermal convection, thus allowing assessing the role of thermal radiation as stimulus for learning. Furthermore, in the training and test situation any heating of the forager's body surface except at the head was prevented, because radiation was shielded from all body parts other than the head (Fig. 1C). Foragers experiencing a heated Peltier plate during the 10 training trials (group $5^{\circ} \mathrm{C}$ shield, $n=20$ ) showed a learned thermal preference in the non-rewarded test trial (Fig. 3B; $\chi^{2}=$ 6.40 , df $=1, p<0.05)$. In contrast, trained foragers of the control group $(n=20)$ slightly, although not statistically

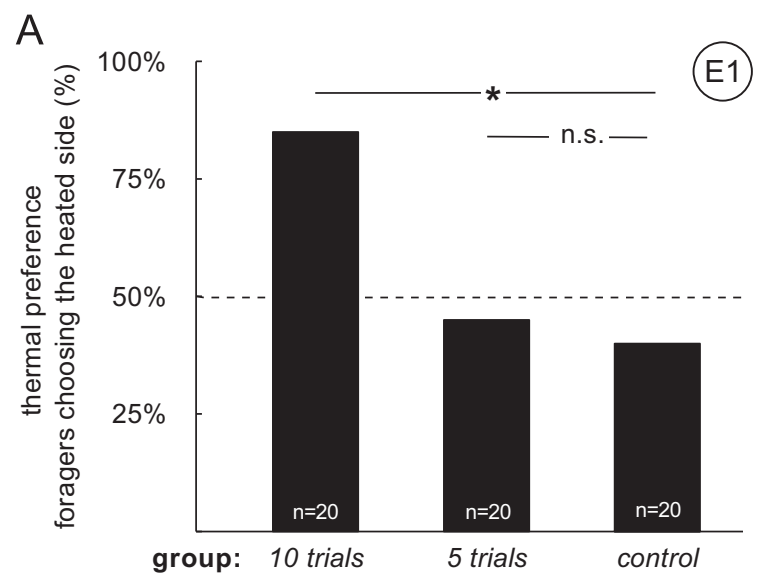

B

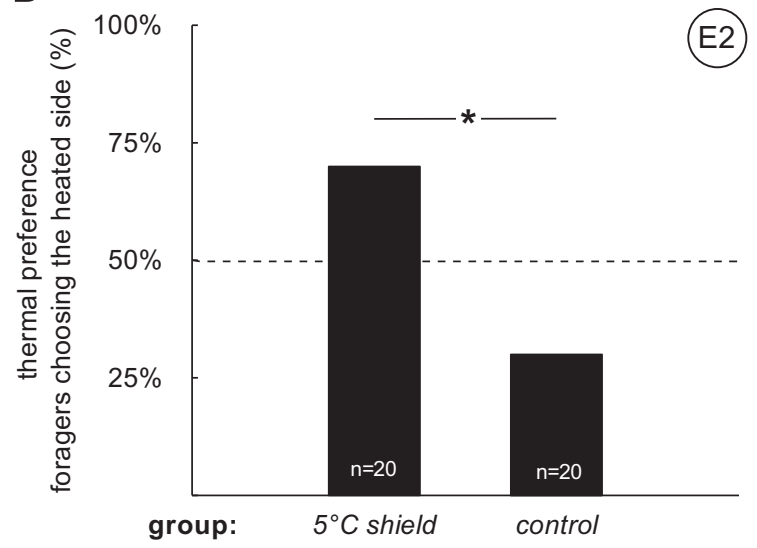

C

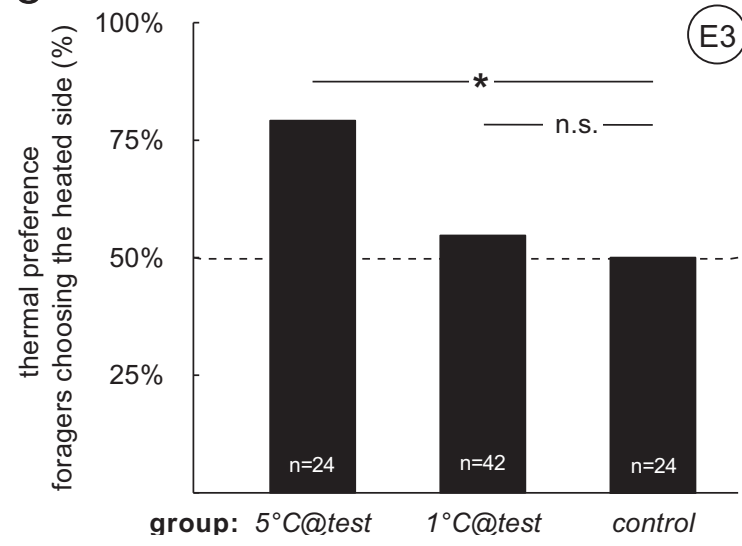

significant, tended to avoid the side with the thermal stimulus $\left(\chi^{2}=1.67, \mathrm{df}=1, p=0.17\right)$.

\subsection{E3: radiation vs. conduction}

The ability of foragers to sense thermal radiation does not exclude the possibility that conductive heat can also be sensed and used as a potent temperature stimulus for learning. In order to investigate how sensitive foragers are to conductive heat, we modified the whole experimental setup and used a paradigm of differential conditioning. After the 10 training trials experiencing a Peltier Plate heated $5{ }^{\circ} \mathrm{C}$ above ambient temperature, workers belonging to different groups experienced in the 11 th trial (first test trial) either a Peltier plate heated $5^{\circ} \mathrm{C}$ above ambient temperature, as during training (group $5^{\circ} \mathrm{C}$ (a) test), or a plate heated $1{ }^{\circ} \mathrm{C}$ above ambient temperature (group1ㄷtest).

Only foragers of the group $5{ }^{\circ} \mathrm{C} @$ test $(n=24)$ showed a significant learned thermal preference in the first test trial (Fig. $3 \mathrm{C} ; \chi^{2}=4.46$, df $=1, p<0.05$ ). Foragers of the group $1{ }^{\circ} \mathrm{C} @$ test $(n=42)$ showed no preference in the first test trial, when one Peltier plate was heated only $1{ }^{\circ} \mathrm{C}$ above ambient temperature (Fig. $3 \mathrm{C} ; \chi^{2}=0.14, \mathrm{df}=1, p=0.45$ ). Differential conditioning allowed for analysis of the dynamic of the learned thermal preference during training of all foragers $(n=66)$. In the first eight training trials, foragers showed no learned thermal preference (Fig. 4; $\chi^{2} \leqslant 2.50$, df $\left.=1, p>0.05\right)$. This indicates that during the initial training trials, foragers find the reward on the T-bar based on exploration of both sides rather than based on, e.g., odor cues present at the bifurcation. In the last two training trials, foragers showed a learned thermal preference (9th trial: $\chi^{2}=4.51$, $\mathrm{df}=1, p<0.05 ; 10$ th trial:

Fig. 3. Thermal preference of foragers plotted as the percentage of workers choosing the heated side during the non-rewarded test situation. The $50 \%$ level indicates no preference for a thermal stimulus. (A) Learning experiment (E1). After 10 training trials (group 10 trials) foragers showed a significant and learned thermal preference compared to the control group $\left(\chi^{2}=8.64\right.$, df $=1, p<0.01$ ); after five training trials (group 5 trials) no learned thermal preference was found $\left(\chi^{2}=0.10, \mathrm{df}=1, p=0.50\right)$. In the test situation, one Peltier plate was heated while the other was cooled $\left(\Delta T=10^{\circ} \mathrm{C}\right)$. (B) Radiation-convection experiment (E2). A laminar upward flow of ambient air had no influence on the learned thermal preference after 10 training trials (group $5^{\circ} \mathrm{C}$ shield) compared to the control group $\left(\chi^{2}=6.40, \mathrm{df}=1, p<0.05\right)$. In the test situation, one Peltier plate was heated while the other had ambient temperature $\left(\Delta T=5^{\circ} \mathrm{C}\right)$. Foragers of the control group slightly, although not statistically significant, tended to avoid the side. The Peltier plate was at $5^{\circ} \mathrm{C}$ above ambient temperature in the test situation $\left(\chi^{2}=1.67, \mathrm{df}=1, p=0.17\right)$. $(\mathrm{C})$ : Radiation-conduction experiment (E3). A significant and learned thermal preference of foragers was measured when the Peltier plate was at $5{ }^{\circ} \mathrm{C}$ above ambient temperature (group $5{ }^{\circ} \mathrm{C}$ @test) in the test situation $\left(\chi^{2}=4.46\right.$, df $\left.=1, p<0.05\right)$. No learned thermal preference was found when the Peltier plate was only $1{ }^{\circ} \mathrm{C}$ above ambient temperature (group $1{ }^{\circ} \mathrm{C}$ @test $)$ in the test situation $\left(\chi^{2}=0.14, \mathrm{df}=1, p=0.45\right)$. Note that foragers of the control group partitioned exactly 1:1 at the bifurcation of the T. Differences between groups were evaluated with the $\chi^{2}$-test and Fishers exact $p$, one-tailed, asterisks denote significant differences at the $5 \%$ level. 


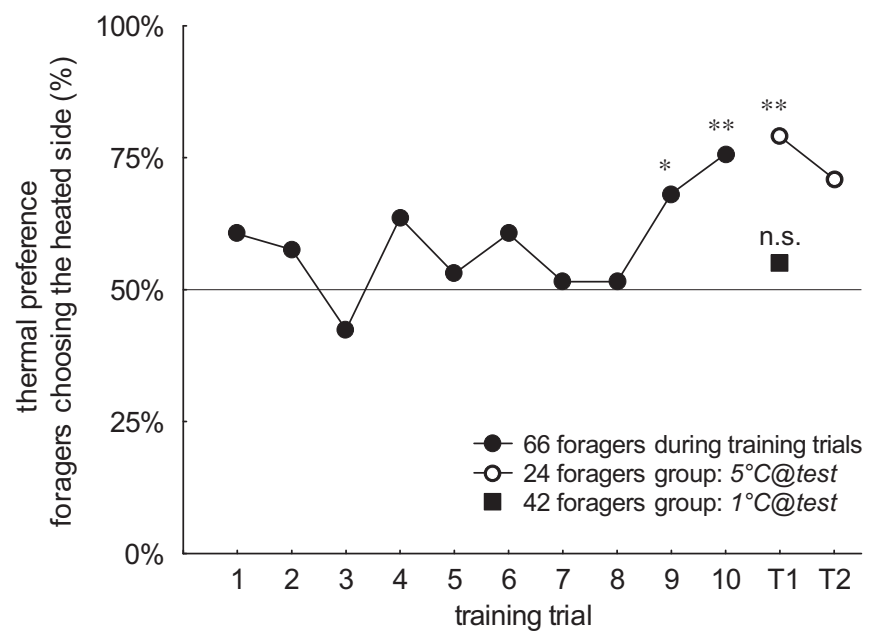

Fig. 4. Thermal preference of 66 foragers on 10 successive training trials (closed circles) in the radiation-conduction experiment (E3). In the first eight training trials, foragers showed no learned thermal preference $\left(\chi^{22} \leqslant 2.50, \mathrm{df}=1, p>0.05\right)$. In the 9 th and 10 th training trial the foragers showed a significant and learned thermal preference compared to an expected 1:1 partitioning (9th trial: $\chi^{22}=4.51, \mathrm{df}=1, p<0.05$; 10 th trial: $\left.\chi^{22}=9.38, \mathrm{df}=1, p<0.01\right)$. In the test situation ( 11 th trial), the foragers had a thermal preference as indicated with open circles (group $5{ }^{\circ} \mathrm{C} @$ test) or a square (group $1{ }^{\circ} \mathrm{C} @$ test), as shown in Fig. 3C. The 50\% level indicates no thermal preference and a 1:1 distribution of foragers' responses to either side. Foragers of the group $5{ }^{\circ} \mathrm{C} @$ test were tested twice and the thermal preference did not change significantly between the first and the second non-rewarded test trial (T1 vs. T2; $\chi^{2}=0.44$, df $=1$, $p>0.05)$.

$\left.\chi^{2}=9.38, \mathrm{df}=1, p<0.01\right)$. Analysis of the group of foragers that was tested with one Peltier plate heated $1^{\circ} \mathrm{C}$ above ambient temperature (group $1{ }^{\circ} \mathrm{C} @$ test, $n=42$ ) revealed a learned thermal preference during the last training trial (10th trial: $\left.\chi^{2}=4.04, \mathrm{df}=1, p<0.05\right)$, yet they failed to show a preference during test, as indicated above. All foragers that were tested with one Peltier plate heated $5{ }^{\circ} \mathrm{C}$ above ambient temperature (group $5{ }^{\circ} \mathrm{C} @$ test, $n=24$ ) could be tested again (second test trial), although the first test trial was not rewarded and thus possibly acted as an extinction trial. The learned thermal preference was slightly reduced, although statistically not significantly, compared to the first test trial (Fig. $4 ; \chi^{2}=0.44$, df $=1$, $p>0.05)$.

\section{Discussion}

In insects, the thermal environment is decisive in influencing many different physiological processes (Beck, 1983). Regarding metabolic control, insects function optimally within a more-or-less limited range of temperatures (Lighton, 1989). Besides its effects on developmental speed and colony growth rates in social insects (Porter, 1988), temperature is also used by insects during hostfinding or to locate appropriate places for reproduction (Bradshaw, 1980; Davis and Sokolove, 1975; Lazzari and Núñez, 1989; Schmitz and Bleckmann, 1998). Thermal cycles, in addition, are powerful entrainment agents for circadian and circannual rhythms in insects (Dreisig, 1976; North, 1993), and social insects in particular proved to be especially sensitive to thermal changes (Roces and Núñez, 1995, 1996).

In the present study, we show that workers of the leafcutting ant $A$. vollenweideri are able to learn the location of a leaf fragment by using a heated object as orientation stimulus in a foraging context. Thermal radiation was the adequate stimulus modality, and a Peltier plate served as orientation stimulus when presented at a distance of $25 \mathrm{~mm}$ and heated $5^{\circ} \mathrm{C}$ above ambient temperature.

For leaf-cutting ants, behavioral responses to thermal cues have previously been described in the context of nest climate control (Bollazzi and Roces, 2002; Kleineidam et al., 2001). Inside the subterranean nest, thermal radiation (e.g. originating from the fungus garden), may be used for orientation. Workers were observed to respond to unsuitable temperatures for their symbiotic fungus and developing brood by relocating them (Bollazzi and Roces, 2002).

The ability to use thermal radiation as a learned orientation cue possibly allows foragers to improve their foraging efficiency. Leaf-cutting ants travel between food resources and nest by using a system of chemically marked foraging trails (Kost et al., 2005). Pheromonal and architectural manipulations of these otherwise directionless trails provide foragers with additional orientation cues (Guajara et al., 1990; Vilela et al., 1987), and there is recent evidence that foraging workers may exploit the Earth's magnetic field to infer direction (Banks and Srygley, 2003). Once a potential food source such as a palatable plant has been located, temperature discontinuities at a small scale may guide foraging workers to find leaves warmed by the sun, which have been shown to be highly palatable (Folgarait et al., 1996; Nichols-Orians, 1991).

Foragers in our experiments were able to use a thermal stimulus for orientation, yet they needed more than five training trials for successful learning. In the context of foraging, learning of food odors by leaf-cutting ants was shown to be very powerful. In Acromyrmex lundi, a single reward sufficed to change the response of workers (Roces, 1990, 1994). Recently, a study investigating odor discrimination of individual Camponotus ants by using differential conditioning showed that more than 20 trials are necessary for full acquisition (Dupuy et al., 2006). In the ant Camponotus rufipes, experiencing a predictable food source four times suffices to change workers' decision rules (Schilman and Roces, 2003). When solving difficult discrimination tasks in the context of color learning and 'delayed matching-to-sample' paradigms, bees also require a large number of training trials (Dyer and Chittka, 2004; Dyer and Neumeyer, 2005; Giurfa, 2004; Giurfa et al., 2001).

We are aware that the use of 10 training trials in our experiments may have not sufficed for the ants to achieve a full acquisition, since the thermal preference increased up to the last training trial (see Fig. 4). More training trials 
may have further increased the thermal preference, and possibly foragers would have also been able to learn temperature differences smaller than $5^{\circ} \mathrm{C}$ as orientation cues. This aspect remains to be investigated.

We used the learning abilities of ants as a tool to investigate what kind of thermal stimuli (thermal radiation or convective heat) can be learned by the foragers, without further consideration of the learning processes underlying the observed flexibility in behavior. However, our data on the behavioral response of leaf-cutting ants to reinforced thermal stimuli are consistent with an associative learning process. In order to classify the observed performance as associative learning, further experiments for instance to trace the acquisition and extinction curves are needed. In experiment E3 we tested the trained foragers twice. The first non-rewarded test is expected to act as an extinction trial, and in line with this argument, a tendency towards a reduced thermal preference was observed. We decided not to perform further test (extinction) trials because the lack of a reward would have probably induced workers to give up and not to voluntarily return to the test situation.

The learning of a thermal stimulus in leaf-cutting ants is probably not a very difficult task requiring advanced cognitive abilities. Rather, a thermal stimulus is unlikely to be such as prominent as for instance odor stimuli, and it might be less represented in the perception of the foragers at the beginning of the training. Whether repeated thermal stimulation during training improves the attention to thermal stimuli in general, remains to be shown. The foragers in our experiments moved their antennae from side to side and raised their body (scanning behavior) at the point of decision, just before climbing on one of the two sticks offered, and this may indicate an active search for the learned thermal stimulus. Although this behavior was not quantified, it might be a measure for the forager's expectancy in the choice situation.

Regarding learning responses to temperature, honeybees are able to learn the location of a feeder based on its temperature, being able to resolve a temperature difference beyond $2{ }^{\circ} \mathrm{C}$ in a choice set-up (Heran, 1952). More recently, bumble bees were shown to prefer warmer flowers and are able to associate the temperature of a feeder with its color (Dyer et al., 2006). Bumble bees' preferences were significant when the temperature difference was $4{ }^{\circ} \mathrm{C}$ or more. In Heran's (1952) study, bees were unable to use thermal radiation for orientation, and it is still an open question whether bees and bumble bees use thermal radiation, convective, and/or conductive heat as orientation stimuli when landing on flowers.

Our experiments provide strong evidence that thermal radiation is indeed an adequate stimulus used by leafcutting ant foragers. A heated object emits energy to the surrounding air by conduction and thermal radiation (IR-radiation). Whereas heated air is transported away from the surface by convection, thermal radiation is not affected by air currents. In our second experiment (E2, radiation vs. convection), we used an air current to drag warm air from both the surface of the Peltier plate and the forager's head. The experimental airflow might have induced turbulences around, e.g., the platform where the reward was presented, and the possibility that some filaments of warm air might still have contacted the forager's sensory organs cannot be excluded. In the test situation, however, the shield protected the forager much better from warm air currents. It is important to mention that in the control group, foragers tended to avoid the warm side during the test. Although speculative, it is tempting to consider that during training, foragers might have experienced a cold stimulus due to evaporative cooling caused by the air current, and therefore tended to prefer the cold side during the test. This possibility remains to be explored in the future.

The results from experiments E1 and E2 showed that thermal radiation was an effective stimulus in the rage of a few centimeters. The same heated object was also used in experiment E3 where foragers were allowed to touch its surface. The temperature difference necessary to allow a learned thermal preference of foragers in the experiment E3 was in the same range as the temperature difference in the experiments where foragers could not touch the Peltier plate $\left(5^{\circ} \mathrm{C}\right.$ above ambient temperature). In addition, a similar number of training trials was necessary to allow learning. We addressed the question whether temperature differences smaller than $5^{\circ} \mathrm{C}$ suffice as a learned cue for orientation. Since the thermal source was in the close range and could be directly contacted, it was expected that foragers should be able to learn and use heated objects with smaller temperature differences for orientation. Ants and bees are able to resolve temperature differences as small as $0.2-0.25^{\circ} \mathrm{C}$ when searching for suitable temperatures for themselves or their brood (Herter, 1924; Heran, 1952; Roces and Núñez, 1995). Surprisingly, we found that foragers trained and tested at a $\Delta T$ of $1{ }^{\circ} \mathrm{C}$ between the two Peltier plates did not prefer the warm side (10 foragers tested, data not shown). Foragers trained at a $\Delta T$ of $5^{\circ} \mathrm{C}$ that showed a learned thermal preference when tested at a $\Delta T$ of $5^{\circ} \mathrm{C}$ failed to show a preference when tested at a $\Delta T$ of $1{ }^{\circ} \mathrm{C}$. It is suggested that foragers might be able to discriminate an object heated only $1{ }^{\circ} \mathrm{C}$ above ambient temperature, but they are unable to use it as a learned orientation cue. It is an open question whether more than 10 training trials would be necessary to allow learning.

Two lines of evidence indicate that thermal radiation is the major stimulus used by ant foragers for orientation. First, our results of experiment E2 in which convective heat was precluded by an air current showed that the foragers still could use the learned thermal stimulus for orientation. Second, our results of experiment E3 in which, although both conductive and convective heat transfer to the antenna were not prevented, the learning performance remained similar to that of experiment E2. Nevertheless, convective or conductive heat may also activate the receptor neurons responsible for sensing thermal radiation, 
and convective heat may carry information used by foragers in a different context than orientation, e.g., nest construction.

For a number of insect species, the sensilla housing thermo receptive neurons have been identified. In most cases, the thermo receptive neuron is associated with two hygroreceptive neurons (triad) in one sensillum (Altner and Loftus, 1985; Ehn and Tichy, 1996; Steinbrecht, 1998). An extreme adaptation for thermo reception was found in, e.g., Buprestid beetles of the genus Melanophila with elaborated cuticular structures of the sensillum and a single IR receptive neuron (Schmitz and Bleckmann, 1997). In Hymenoptera, the thermo receptive neurons are located in sensilla coeloconica and/or sensilla ampullacea (Dumpert, 1978; Kleineidam and Tautz, 1996; Lacher, 1964). The thermo receptive neurons of several insect species seem to be adapted for reception of convective heat (Gingl et al., 2005; Gingl and Tichy, 2001). However, the ability to use thermal radiation was also shown for other insects beside the fire-beetles, e.g., for the haematophagous bugs Triatoma infestans (Lazzari and Núñez, 1989) and Rhodnius prolixus (Schmitz et al., 2000). Unfortunately, the physiology and morphology of thermo receptive neurons and sensillar structures reported so far for Hymenoptera do not allow any conclusive view whether convective heat or thermal radiation is the adequate stimulus modality. The question whether the sensilla responsible for the reception of thermal radiation are direction-sensitive is still open, and we are far from understanding how temperature cues are processed in the insect brain and how the thermal environment is perceived by insects.

\section{Acknowledgments}

The leaf-cutting ant colonies used during this study were collected at the Reserva Ecológica El Bagual (Alparamis SA-Aves Argentinas) in eastern Chaco, Province of Formosa, Argentina. We are very much indebted to the ornithologist Alejandro G. Di Giacomo, his field assistants, and especially the family Götz for providing facilities and much help at the Biological Station during our stays. Many thanks to Silvia Naranjo Blanco, Franz Gruber and Yi-chun Chen for help in several of the experiments reported here. Financial support was provided by the DFG, Germany (SFB 554, A6 and E1) and DAAD (Vigoni $\mathrm{D} / 05 / 54047)$.

\section{References}

Altner, H., Loftus, R., 1985. Ultrastructure and function of insect thermoand hygroreceptors. Annual Review of Entomology 30, 273-295.

Autuori, M., 1941. Contribuição para o conhecimento da saúva (Atta spp.-Hymenoptera-Formicidae). I-Evolução do saúveiro (Atta sexdens rubropilosa Forel, 1908). Arquivos do Instituto Biológico 12, 197-228.

Banks, A., Srygley, R.B., 2003. Orientation by magnetic field in leaf-cutter ants, Atta colombica (Hymenoptera: Formicidae). Ethology 109, 835-846.
Beck, S.D., 1983. Insect thermoperiodism. Annual Review of Entomology 28, 91-108.

Bollazzi, M., Roces, F., 2002. Thermal preference for fungus culturing and brood location by workers of the thatching grass-cutting ant Acromyrmex heyeri. Insectes Sociaux 49, 153-157.

Bradshaw, W.E., 1980. Thermoperiodism and the thermal environment of the pitcher-plant mosquito, Wyeomyia smithii. Oecologia 46, 13-17.

Brian, M.V., 1952. The structure of a dense natural ant population. Journal of Animal Ecology 38, 12-24.

Brian, M.V., 1973. Temperature choices and its relevance to brood survival and caste determination in the ant Myrmica rubra L. Physiological Zoology 46, 245-252.

Calabi, P., Porter, S.D., 1989. Worker longevity in the fire ant, Solenopsis invicta: ergonomic considerations of correlations between temperature, size and metabolic rates. Journal of Insect Physiology 35, 643-649.

Davis, E.E., Sokolove, P.G., 1975. Temperature response of antennal receptors of the mosquito, Aedes aegypti. Journal of Comparative Physiology 96, 223-236.

Dreisig, H., 1976. Phase shifting the circadian rhythms of nocturnal insects by temperature changes. Physiological Entomology 1, 123-129.

Dumpert, K., 1978. Das Sozialleben der Ameisen. Paul Parey, Berlin.

Dupuy, F., Sandoz, J.C., Giurfa, M., Josens, R., 2006. Individual olfactory learning in Camponotus ants. Animal Behaviour 72, 1081-1091.

Dyer, A.G., Chittka, L., 2004. Bumblebees (Bombus terrestris) sacrifice foraging speed to solve difficult colour discrimination tasks. Journal of Comparative Physiology A 190, 759-763.

Dyer, A.G., Neumeyer, C., 2005. Simultaneous and successive colour discrimination in the honeybee (Apis mellifera). Journal of Comparative Physiology A 191, 547-557.

Dyer, A.G., Whitney, H.M., Arnold, S.E.J., Glover, B.J., Chittka, L., 2006. Bees associate warmth with floral colour. Nature 442, 525.

Ehn, R., Tichy, H., 1996. Threshold for detecting temperature changes in a spider thermoreceptor. Journal of Neurophysiology 76, 2608-2613.

Folgarait, P.J., Dyer, L.A., Marquis, R.J., Braker, H.E., 1996. Leafcutting ant preferences for five native tropical plantation tree species growing under different light conditions. Entomologia Experimentalis et Applicata 80, 521-530.

Frouz, J., 1996. The role of nest moisture in thermoregulation of ant (Formica polyctena, Hymenoptera, Formicidae) nests. Biologia (Bratislava) 51, 541-547.

Gingl, E., Tichy, H., 2001. Infrared sensitivity of thermoreceptors. Journal of Comparative Physiology A. 187, 467-475.

Gingl, E., Hinterwirth, A., Tichy, H., 2005. Sensory representation of temperature in mosquito warm and cold cells. Journal of Neurophysiology 94, 176-185.

Giurfa, M., 2004. Conditioning procedure and color discrimination in the honeybee Apis mellifera. Naturwissenschaften 91, 228-231.

Giurfa, M., Zhang, S., Jenett, A., Menzel, R., Srinivasan, M.V., 2001. The concepts of 'sameness' and 'difference' in an insect. Nature 410, 930-933.

Guajara, M.S., Vilela, E.F., Jaffé, K., 1990. Senses used by Acromyrmex subterraneus molestans during homing orientation, under laboratory conditions. In: Vander Meer, R.K., Jaffé, K. (Eds.), Applied Myrmecology-A World Perspective. Westview Press, Boulder, pp. 367-372.

Heinrich, B., 1993. The Hot-Blooded Insects - Strategies and Mechanisms of Thermoregulation. Springer, Berlin.

Heran, H., 1952. Untersuchungen über den Temperatursinn der Honigbiene (Apis mellifica) unter besonderer Berücksichtigung der Wahrnehmung strahlender Wärme. Zeitschrift für vergleichende Physiologie 34, 179-206.

Herter, K., 1924. Untersuchungen über den Temperatursinn einiger Insekten. Zeitschrift für vergleichende Physiologie 1, 221-288.

Hubbell, S.P., Johnson, L.K., Stanislav, E., Wilson, B., Fowler, H., 1980. Foraging by bucket-brigade in leaf-cutter ants. Biotropica 12, 210-213.

Jaffe, K., Howse, P.E., 1979. The mass recruitment system of the leaf cutting ant, Atta cephalotes (L.). Animal Behaviour 27, 930-939. 
Kleineidam, C., Tautz, J., 1996. Perception of carbon dioxide and other "air-condition" parameters in the leaf cutting ant Atta cephalotes. Naturwissenschaften 83, 566-568.

Kleineidam, C., Roces, F., 2000. Carbon dioxide concentrations and nest ventilation in nests of the leaf-cutting ant Atta vollenweideri. Insectes Sociaux 47, 241-248.

Kleineidam, C., Romani, R., Tautz, J., Isidoro, N., 2000. Ultrastructure and physiology of the $\mathrm{CO}_{2}$ sensitive sensillum ampullaceum in the leafcutting ant Atta sexdens. Arthropod Structure \& Development 29, 43-55.

Kleineidam, C., Ernst, R., Roces, F., 2001. Wind-induced ventilation of the giant nests of the leaf-cutting ant Atta vollenweideri. Naturwissenschaften 88, 301-305.

Kost, C., de Oliveira, E.G., Knoch, T.A., Wirth, R., 2005. Spatiotemporal permanence and plasticity of foraging trails in young and mature leaf-cutting ant colonies (Atta spp.). Journal of Tropical Ecology 21, 677-688.

Lacher, V., 1964. Elektrophysiologische Untersuchungen an einzelnen Rezeptoren für Geruch, Kohlendioxid, Luftfeuchtigkeit und Temperatur auf den Antennen der Arbeitsbiene und der Drohne (Apis mellifera L.). Zeitschrift für vergleichende Physiologie 48, 587-623.

Lazzari, C.R., Núñez, J.A., 1989. The response to radiant heat and the estimation of the temperature of distant sources in Triatoma infestans. Journal of Insect Physiology 35, 525-529.

Lighton, J.R.B., 1989. Individual and whole-colony respiration in an African formicine ant. Functional Ecology 3, 523-530.

Moreira, A.A., Forti, L.C., Boaretto, M.A.C., Andrade, A.P.P., Lopes, J.F.S., Ramos, V.M., 2004a. External and internal structure of Atta bisphaerica Forel (Hymenoptera: Formicidae) nests. Journal of Applied Entomology 128, 204-211.

Moreira, A.A., Forti, L.C., de Andrade, A.P.P., Boaretto, M.A.C., Lopes, J.F.S., 2004b. Nest architecture of Atta laevigata (F. Smith, 1858) (Hymenoptera: Formicidae). Studies on the Neotropical Fauna and Environment 39, 109-116.

Nichols-Orians, C.M., 1991. The effects of light on foliar chemistry, growth and susceptibility of seedlings of a canopy tree to an attine ant. Oecologia 86, 552-560.

North, R.D., 1993. Entrainment of the circadian rhythm of locomotor activity in wood ants by temperature. Animal Behaviour 45, 393-397.

Porter, S.D., 1988. Impact of temperature on colony growth and developmental rates of the ant, Solenopsis invicta. Journal of Insect Physiology 34, 1127-1133.

Porter, S.D., Tschinkel, W.R., 1993. Fire ant thermal preferences: behavioral control of growth and metabolism. Behavioral Ecology and Sociobiology 32, 321-329.

Powell, R.J., Stradling, D.J., 1986. Factors influencing the growth of Attamyces bromatificus, a symbiont of attine ants. Transactions of the British Mycological Society 87, 205-213.

Quinlan, R.J., Cherrett, J.M., 1978. Aspects of the symbiosis of the leafcutting ant Acromyrmex octospinosus (Reich) and its food fungus. Ecological Entomology 3, 221-230.
Roces, F., 1990. Olfactory conditioning during the recruitment process in a leaf-cutting ant. Oecologia 83, 261-262.

Roces, F., 1994. Odour learning and decision-making during food collection in the leaf-cutting ant Acromyrmex lundi. Insectes Sociaux 41, 235-239.

Roces, F., 1995. Variable thermal sensitivity as output of a circadian clock controlling the bimodal rhythm of temperature choice in the ant Camponotus mus. Journal of Comparative Physiology A 177, 637-643.

Roces, F., Kleineidam, C., 2000. Humidity preference for fungus culturing by workers of the leaf-cutting ant Atta sexdens rubropilosa. Insectes Sociaux 47, 348-350.

Roces, F., Núñez, J.A., 1989. Brood translocation and circadian variation of temperature preference in the ant Camponotus mus. Oecologia 81, 33-37.

Roces, F., Núñez, J.A., 1995. Thermal sensitivity during brood care in workers of two Camponotus ant species: circadian variation and its ecological correlates. Journal of Insect Physiology 41, 659-669.

Roces, F., Núñez, J.A., 1996. A circadian rhythm of thermal preference in the ant Camponotus mus: masking and entrainment by temperature cycles. Physiological Entomology 21, 138-142.

Röschard, J., Roces, F., 2003a. Cutters, carriers and transport chains: distance-dependent foraging strategies in the grass-cutting ant Atta vollenweideri. Insectes Sociaux 50, 237-244.

Röschard, J., Roces, F., 2003b. Fragment-size determination and sizematching in the grass-cutting ant Atta vollenweideri depend on the distance from the nest. Journal of Tropical Ecology 19, 647-653.

Scherba, G., 1962. Mound temperatures of the ant Formica ulkei Emery. American Midland Naturalist 67, 373-385.

Schilman, P.E., Roces, F., 2003. Assessment of nectar flow rate and memory for patch quality in the ant Camponotus rufipes. Animal Behaviour 66, 687-693.

Schmitz, H., Bleckmann, H., 1997. Finestructure and physiology of the infrared receptor of beetles of the genus Melanophila (Coleoptera: Buprestidae). International Journal of Insect Morphology \& Embryology 26, 205-215.

Schmitz, H., Bleckmann, H., 1998. The photomechanic infrared receptor for the detection of forest fires in the beetle Melanophila acuminata (Coleoptera: Buprestidae). Journal of Comparative Physiology A 182, 647-657.

Schmitz, H., Trenner, S., Hofmann, M.H., Bleckmann, H., 2000. The ability of Rhodnius prolixus (Hemiptera; Reduviidae) to approach a thermal source solely by its infrared radiation. Journal of Insect Physiology 46, 745-751.

Steinbrecht, R.A., 1998. Bimodal thermo- and hygrosensitive sensilla. In: Harrison, F.W., Locke, M. (Eds.), Microscopic Anatomy of Invertebrates, vol. 11B. Wiley-Liss, Lissabon, pp. 405-422.

Steiner, A., 1929. Temperaturuntersuchungen in Ameisennestern mit Erdkuppeln, im Nest von Formica exsecta nyl. und in Nestern unter Steinen. Zeitschrift für vergleichende Physiologie 9, 1-66.

Vilela, E.F., Jaffé, K., Howse, P.E., 1987. Orientation in leaf-cutting ants (Formicidae: Attini). Animal Behaviour 35, 1443-1453. 